\title{
STRUCTURE AND MAGNETIC PROPERTIES IN THE MIXTURE OF FE AND BN POWDERS AFTER HIGH-ENERGY BALL MILLING AND ANNEALING
}

\author{
Vladimir MENUSHENKOV, Irina MINKOVA, Alexander SAVCHENKO, Igor SHCHETININ, \\ Dmitry ZHUKOV, Sandra MECALA \\ National University of Science and Technology "MISIS", 119049 Leninskyi pr. 4, Moscow, Russia, \\ menushenkov@gmail.com
}

https://doi.org/10.37904/metal.2020.3585

\begin{abstract}
The effect of high-energy ball milling a mixture of $\mathrm{Fe}$ and $\mathrm{h}-\mathrm{BN}$ with weight ratio of $\mathrm{Fe}: \mathrm{BN}=15,4,1,0.36$ on the phase composition and magnetic properties of the synthesized material has been investigated. Highenergy ball milling demonstrated a significant change in the phase content, structure, and magnetic characteristics upon MA and followed annealing at $600{ }^{\circ} \mathrm{C}$, in particular upon annealing, and the coercivity of the MA powder reached $\mathrm{H}_{\mathrm{C}}=43 \mathrm{kA} / \mathrm{m}(540 \mathrm{Oe})$.
\end{abstract}

Keywords: Mechanical alloying, mixture of $\mathrm{Fe}$ and $\mathrm{BN}$, iron nitrides, saturation magnetization, coercivity

\section{INTRODUCTION}

Permanent magnets play a crucial role in new areas of science and technical. Currently, the most widely used permanent magnets are $\mathrm{Nd}_{2} \mathrm{Fe}_{14} \mathrm{~B}$ and $\mathrm{SmC}_{5}$, both containing rare-earth (RE) elements. The $\mathrm{RE}$ crisis has stimulated researchers to investigate new magnetic alloys with moderate properties between hard ferrites and $\mathrm{RE}$ permanent magnets. Among the RE-free hard magnetic materials, the metastable tetragonal $\alpha^{\prime \prime}-\mathrm{Fe}_{16} \mathrm{~N}_{2}$ phase of iron nitrides has attracted considerable attention due to the low cost of $\mathrm{Fe}$ and high magnetization of $\alpha^{\prime \prime}-\mathrm{Fe}_{16} \mathrm{~N}_{2}$. The usual approach to form nitrides is gas-phase interstitial modification [1]. In the past years, the efforts to synthesize bulk samples of the Fe-N phases have been made [2-5]. However, the synthesis of Fe-N alloys by gas-solid reaction is usually difficult to be performed. Therefore, it is of interest in using a kind of solid $\mathrm{N}$ source in producing of new Fe-N phases. It is suggested the BN powder to be as a candidate for new-phase production [6-8]. One of approaches to obtain iron nitrides is the solid-state reactions by mechanical activation milling (mechanical alloying, MA) a mixture of Fe and $h$-BN [9-13] or $\mathrm{Fe}$ and $\mathrm{NH}_{4} \mathrm{NO}_{3}$ [14-17].

The aim of this work thus was to investigate the phase composition, structure and magnetic properties of materials prepared via mechanical alloying of a mixture of $\mathrm{Fe}$ and $\mathrm{h}-\mathrm{BN}$ powders with a weight ratio $\mathrm{Fe}: \mathrm{BN}$ from 15 to 0.36 after their extraction from the mill chamber in the air and upon the subsequent annealing at $600{ }^{\circ} \mathrm{C}$ in the nitrogen atmosphere.

\section{EXPERIMENTAL}

The powder mixtures of Fe (PZhR-3.200.28) and $h$-BN (manufactured by "Plazmoterm") were prepared with weight ratio of $\mathrm{Fe}: \mathrm{BN}=15,8,4,1$ and 0.36 . The high-energy ball milling was carried out in the Aktivator-2S in the nitrogen atmosphere with milling lifetime varied from 7 to $60 \mathrm{~h}$. The MA powders were compacted using press moulding at $40 \mathrm{MPa}$. The pressed samples were annealed within $2-5 \mathrm{~h}$ in the nitrogen atmosphere at 200-600 ${ }^{\circ} \mathrm{C}$. The X-ray phase analysis was performed by diffractometer DRON-4 using CoKa radiation. Qualitative and quantitative phase analyses were done using the software described in [18]. The microstructure of samples was observed in the scanning electronic microscope (SEM) JEOL JSM-6610LV. The differential thermal analysis (DSC) was carried out in the synchronic thermal analyzer Netzsch STA 449 F3 Jupiter (the 
heating rate was $10 \mathrm{~K} / \mathrm{min}$ ). Magnetic properties were examined by the vibrating sample magnetometer VSM 250 (Dexing Magnet Tech Co. Ltd) in magnetic field up to $2.5 \mathrm{~T}$.

\section{RESULTS AND DISCUSSION}

The powder mixtures were studied with ratio of $\mathrm{Fe}: \mathrm{B}=15 ; 8 ; 4 ; 1$ and 0.36 ). It is found that $\alpha$-Fe lines and an $\mathrm{X}$-ray amorphous phase (AP) are identified for the samples with ratio of $\mathrm{Fe}: \mathrm{BN} \leq 4$ by the XRD analysis upon $M A, 60 \mathrm{~h}$, whereas for others, only the $\alpha-F e$ lines are characterized. Figure 1 shows diffraction of $\mathrm{Fe}, \mathrm{h}-\mathrm{BN}$, $\mathrm{Fe}: \mathrm{BN}=1$ powders upon MA, $60 \mathrm{~h}$ and $\mathrm{Fe}: \mathrm{BN}=1$ followed by MA powder annealing at $600{ }^{\circ} \mathrm{C}, 2 \mathrm{~h}$. The MA of pure Fe powder resulted in lines broadening and a slight change in lattice parameter a of $\alpha$-Fe. The period is increased from 0.2866 to $0.2869 \mathrm{~nm}$ upon MA, $60 \mathrm{~h}$ (Figure 1a). Two halos are observed in regions near $\theta$ $=30^{\circ}$ and $50^{\circ}$ in the ground BN-powder spectra (Figure 1b), which indicate X-ray amorphous phase (XAP) formation upon MA, $60 \mathrm{~h}$. In the pattern profile of the MA powder with ratio of Fe:BN $=1$ there are only $\alpha-\mathrm{Fe}$ peaks and the halo near $\theta \approx 30^{\circ}$ occurred (Figure 1c). The lattice period of $\alpha$-Fe is incremented to $0.2872 \mathrm{~nm}$ upon MA, $60 \mathrm{~h}$ due to a feasible presence of $B$ atoms in addition to the $N$ in the interstitial positions of the $\mathrm{Fe}$ lattice. An observed asymmetric broadening of $\mathrm{Fe}(110)$ line in the area of smaller angles indicates the onset of iron nitride formation. Annealing the MA powders at $600^{\circ} \mathrm{C}$ for $2 \mathrm{~h}$ narrowed the $\alpha$-Fe peaks and decreased the volume of XAP, and produced weak new lines at small angles, probably from iron nitrides (Figure 1d).

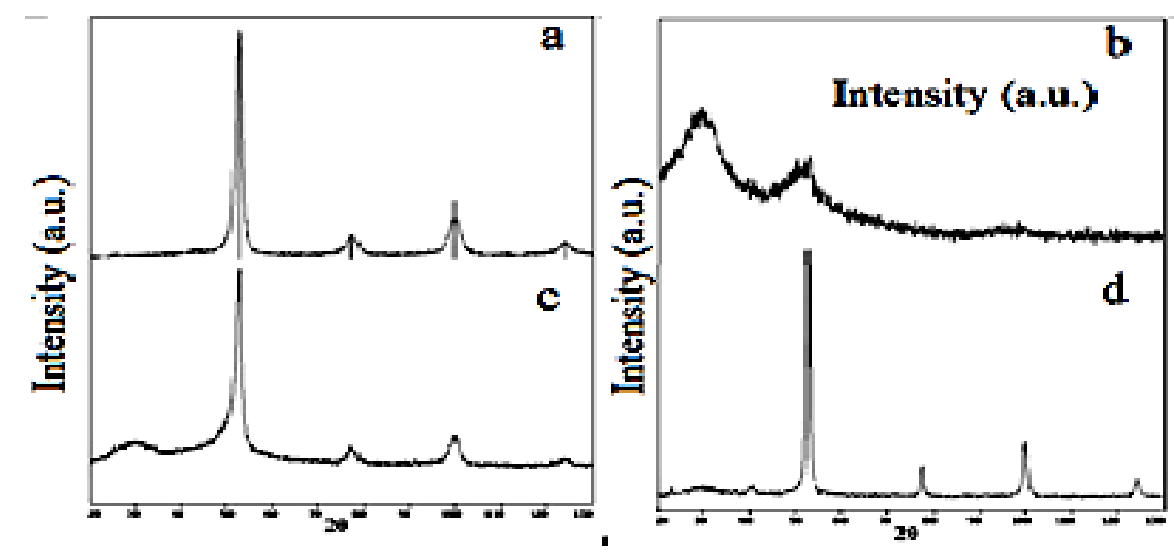

Figure 1 The XRD diffraction patterns of powders upon MA, $60 \mathrm{~h}$ : (a) pure Fe; (b) pure BN; (c) Fe:BN = 1 powder, and (d) the same powder upon annealing at $600^{\circ} \mathrm{C}$. Vertical dashed lines show the $\alpha$-Fe peaks

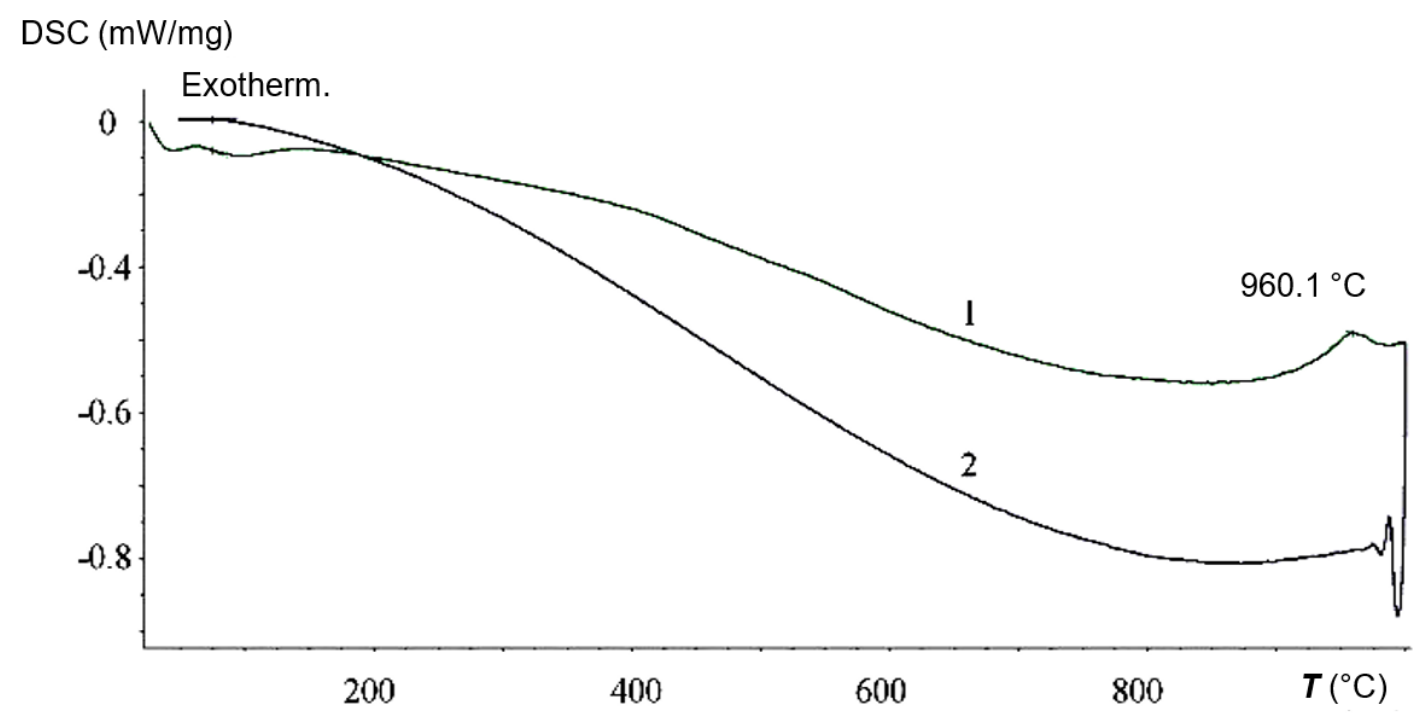

Figure $2 \mathrm{DSC}$ data of the sample Fe:BN = 1 upon MA, $60 \mathrm{~h}$ : (1) heating, (2) cooling 
Differential scanning calorimetry demonstrates (Figure 2) that exothermic maximum on DSC curves in the range of 20 to $700{ }^{\circ} \mathrm{C}$ specific to amorphous phase transformation into crystalline phase, as the first order phase transition, is not observed. Contrarily, the delivered DSC results indicate the endothermic behaviour, besides the sample weight reduce is observed at temperatures exceeding $500^{\circ} \mathrm{C}$.

It is known [19] that after the MA procedure the contact of BN particles with air at the stage of powder extraction from the mill chamber is reported to boron oxides and nitrogen oxides formation. Under the conditions considered in [19], this transformation occurs at temperatures above $1500{ }^{\circ} \mathrm{C}$ at $5.5 \mathrm{GPa}$. Therefore, we assume that the absence of an exothermic peak on DSC curves may be associated with crystallization of amorphous BN, which occurs at temperatures exceeding the data given in Figure 2.

Figure 3 shows the microstructure of the pure Fe powder and Fe:BN =15, 4, 1 powders upon MA, $60 \mathrm{~h}$. The images were obtained via SEM of compacted powders. The pure Fe upon MA (Figure 3a) is consisted of particles with average sizes of 500-3000 nm, some of which have anisotropic shapes. The MA powders of $\mathrm{Fe}: \mathrm{BN}=15$ and 4 are contained of equiaxial particles with sizes of 200-500 nm (Figures 3b,c). The Fe:BN= 1 powder upon MA is contained of low contrast Fe particles (average size, $\sim 100 \mathrm{~nm}$ ) in the amorphous-like matrix phase (Figure 3d).

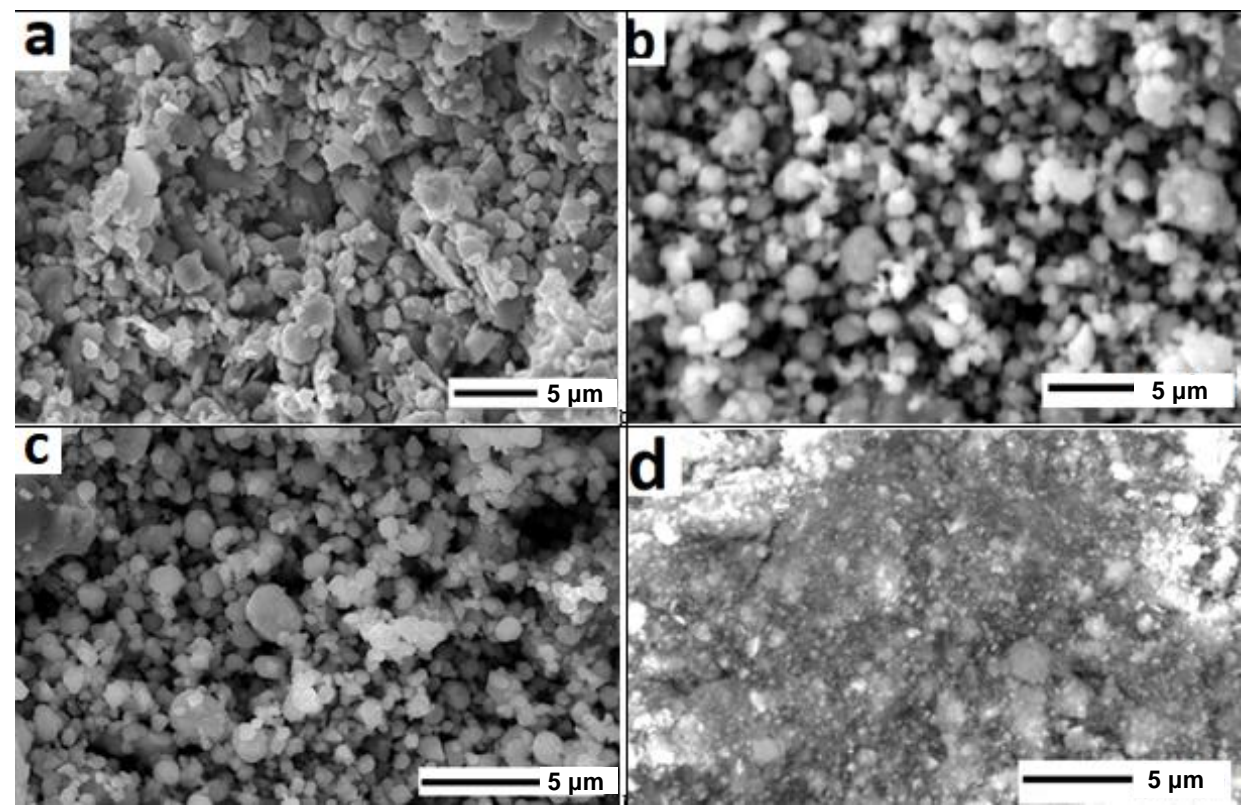

Figure 3 SEM images of the samples upon MA, $60 \mathrm{~h}$ : (a) pure Fe; (b) Fe:BN = 15; (c) $\mathrm{Fe}: \mathrm{BN}=4$ and $\mathrm{Fe}: \mathrm{BN}=1$ (d)
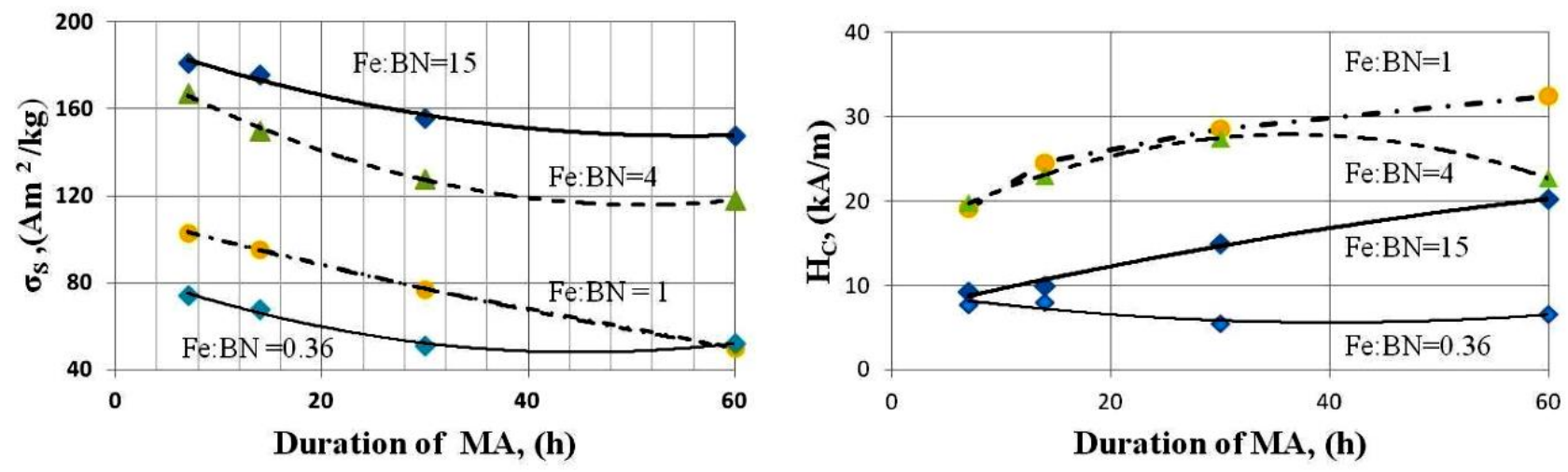

Figure 4 Dependences in $\sigma_{S}$ and $\boldsymbol{H}_{c}$ of the Fe-BN samples upon MA, $60 \mathrm{~h}$ versus MA lifetime 
Figure 4 shows the influence MA duration on magnetic properties of the samples $\mathrm{Fe}: \mathrm{BN}=15,4,1,0.36$ upon MA, $60 \mathrm{~h}$. Apparently, a specific saturation magnetization is reduced monotonically, while the coercivity is increased with the MA lifetime arise to $60 \mathrm{~h}$. The maximal value of $H_{c}$ is observed on MA powders with a weight ratio $\mathrm{Fe}: \mathrm{BN}=1$.

In our previous work [11], the elemental composition of the powder with ratio of $\mathrm{Fe}: \mathrm{BN}=1$ upon $\mathrm{MA}$ for $60 \mathrm{~h}$ via X-ray photoelectron spectroscopy (XPS) has been investigated. The obtained data revealed two processes induced by the high-energy milling of $\mathrm{Fe}$ and $h$-BN mixtures as: i) the physical milling of particles and ii) interaction between mechanically activated particles of $\mathrm{Fe}$ and $\mathrm{BN}$ with atmospheric oxygen and water vapour after their extraction from the mill chamber.

The effect of iron content in the Fe-BN mixture after MA, $60 \mathrm{~h}$ to the size of coherence scattering regions $(<D>)$ and microscopic deformation value $\langle\varepsilon\rangle$ is shown in Figure 5a. The changes of $\langle D\rangle$ and $\langle\varepsilon\rangle$ with increasing duration of MA for the sample $\mathrm{Fe}: \mathrm{BN}=15$ are shown in Figure $\mathbf{5 b}$. The second process results in interaction the MA powder with $\mathrm{O}_{2}$ and $\mathrm{H}_{2} \mathrm{O}$ during the $\mathrm{MA}$, and produces chemical bonds $\mathrm{Fe}-\mathrm{N}, \mathrm{Fe}-\mathrm{B}$, and $\mathrm{Fe}-\mathrm{O}$ on the surfaces of Fe particles due to the formation of iron nitrides, borides, and metahydroxide $\mathrm{FeO}(\mathrm{OH})[20]$. In addition, the interaction between boron and oxygen results in the formation of amorphous $\mathrm{B}_{2} \mathrm{O}_{3}$. The annealing of the $\mathrm{Fe}-\mathrm{BN}$ powders upon MA at temperatures ranging from 200 to $600^{\circ} \mathrm{C}$ in the nitrogen atmosphere leads to the $\mathrm{Fe}_{4} \mathrm{~N}$ nitride formation and decomposition of $\mathrm{FeO}(\mathrm{OH})$, which transforms to oxide $\mathrm{Fe}_{3} \mathrm{O}_{4}$ in the surface layers of $\alpha$-Fe particles.
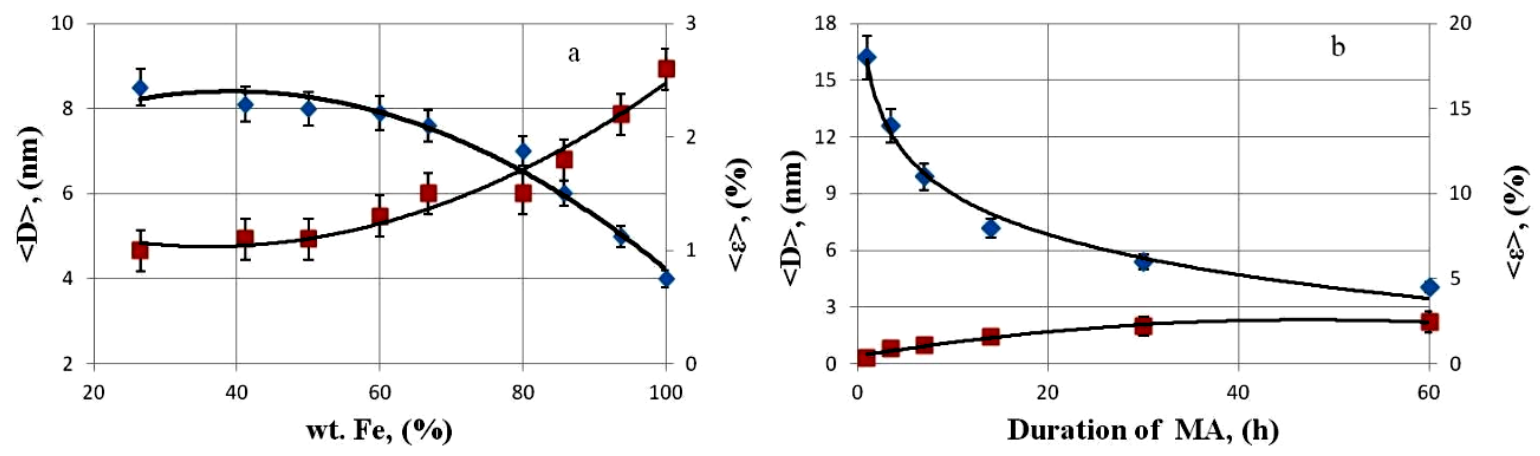

Figure 5 Dependences of $<D>$ size and $<\varepsilon>$ value versus iron contents in the powders Fe-BN upon MA, $60 \mathrm{~h}$

(a) and versus the duration of MA for the sample $\mathrm{Fe}: \mathrm{BN}=15$ (b)

Figure 6 presents the hysteresis loops of the $\mathrm{Fe}: \mathrm{BN}=1$ powder upon $\mathrm{MA}, 60 \mathrm{~h}$ and followed by $2 \mathrm{~h}$ of annealing in the nitrogen atmosphere at $600^{\circ} \mathrm{C}$. All hysteresis characteristics are increased after annealing: $H_{c}$ from 32.5 $\mathrm{kA} / \mathrm{m}$ to $42 \mathrm{kA} / \mathrm{m}, \sigma_{s}$ from 40.6 to $65.7 \mathrm{~A} \cdot \mathrm{m}^{2} / \mathrm{kg}, \sigma_{r}$ from 9 to $15 \mathrm{~A} \cdot \mathrm{m}^{2} / \mathrm{kg}$.
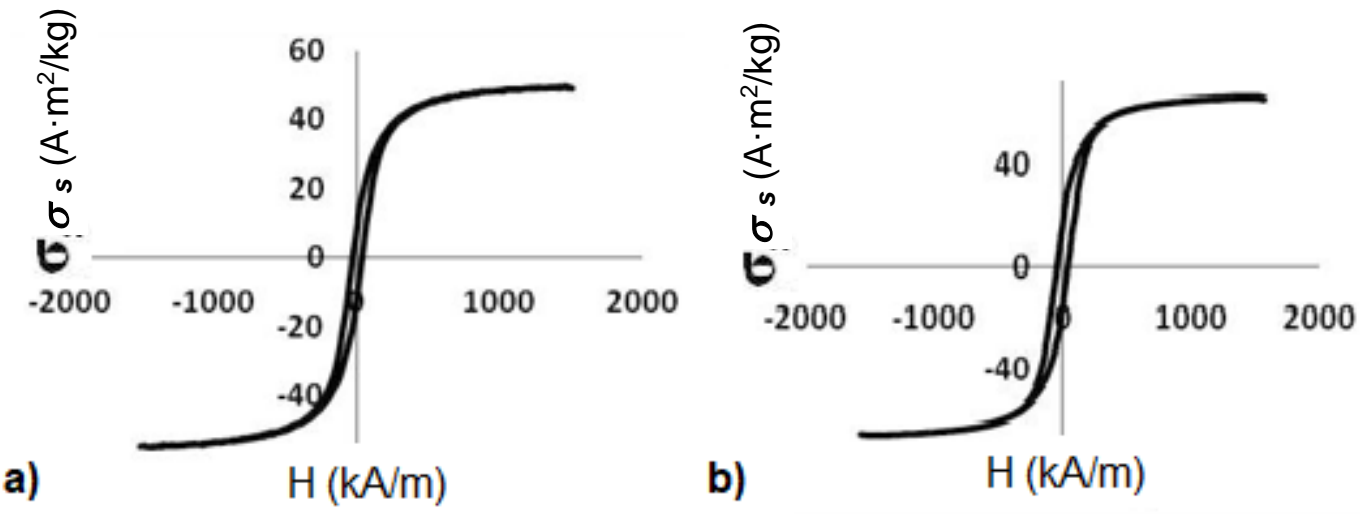

b)

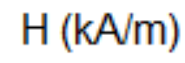

Figure 6 Hysteresis loops of the Fe:BN = 1 powders (a) upon MA, $60 \mathrm{~h}$, and (b) after annealing the MA powders in nitrogen at $600{ }^{\circ} \mathrm{C}$ 
The demagnetization curves analysis demonstrates that the coercivity is related to domain walls pinning on non-equilibrium structural defects (dislocations, vacancies, internal strains, and surface impurities) are originated during MA. The other reason of pinning may be concerned with nanoparticles of oxides and nitrides formed in the surface layer of iron particles during MA and subsequent annealing, when the influence of nonequilibrium structural defects are relaxed and their influence as pinning centres decreased.

\section{CONCLUSION}

Our studies showed that the high-energy milling of $\mathrm{Fe}$ and $\mathrm{h}$-BN powders mixture in a planetary ball mill allows obtaining the magnetically hard material from initially soft magnetic iron. The coercivity of milled powders increases with the raise of the mechanical milling duration.

The annealing of the Fe-BN powders after MA at temperatures ranging from 200 to $600{ }^{\circ} \mathrm{C}$ in the nitrogen atmosphere leads to the nanoparticles $\mathrm{Fe}_{4} \mathrm{~N}$ and $\mathrm{Fe}_{3} \mathrm{O}_{4}$ formation in the surface layers of $\alpha$-Fe particles which resulted in pinning of domain walls and high coercivity. The maximum obtained magnetic properties for the sample Fe:BN $=1$ followed by annealing at $600^{\circ} \mathrm{C}$ within 2 hours in the nitrogen atmosphere as follows: saturation magnetization $\sigma_{s}=66 \mathrm{Am}^{2} / \mathrm{kg}, H_{c}=42 \mathrm{kA} / \mathrm{m}$.

\section{ACKNOWLEDGEMENTS}

This work was supported by the Russian Science Foundation as part of the RF Presidential program "Research Conducted by Scientific Groups Led by Young Scientists," project no. 18-72-10161.

\section{REFERENCES}

[1] COEY, J.M.D., SMITH, P.A.I. Magnetic nitrides. Journal of Magnetism and Magnetic Materials. 1999, 200, pp. 405-424.

[2] GABAY, A.M., HADJIPANAYIS, G.C. Development of ThMn 12 - type compounds for permanent magnets. RareEarth and future permanent magnets and their application (REMP 2016). Darmstadt, 2016, 28.08-01.09 2016 (04-1530). pp. 84-91.

[3] CUI, J., KRAMER, M., ZHOU, L. Current progress and future challenges in rare-earth-free permanent magnet. J. Acta materialia, 2018, vol. 118, pp.118-137.

[4] YEFIMENKO, S.P., ALEXEEV, V.I. Some physical and chemical aspects of nitrogen-alloyed steels production by means of smelting methods. Russian Metallurgy. 2002, no. 1, pp. 10-17.

[5] COSTA, A.R.G., SILVA, R.C., FERREIRA, L.P. et al. Formation of oriented nitrides by N+ion implantation in iron single crystals. Journal of Magnetism and Magnetic Materials. 2014, vol. 350, pp. 129-134.

[6] MINKOVA, I.O., MENUSHENKOV, V.P., SAVCHENKO, A.G., MINKOV, O.B. Formation of iron borides and iron nitrides in interaction of iron powder with boron nitride powder. Materials Research Innovations. 2018, vol. 23, pp. $422-426$.

[7] MINKOVA, I.O., MENUSHENKOV, V.P., SAVCHENKO,,A.G., ZHELEZNIY, M.V. Effect of bulk nitriding on magnetic properties of iron. Metal Science and Heat Treatment. 2018, vol. 60, pp. 539-543.

[8] TAO, J.G., YAO, B., YANG, J.H. Mechanism of formation of Fe-N alloys in the solid-state reaction process between iron and boron nitride. Journal of Alloys and Compounds. 2004, vol. 384, pp. 268-273.

[9] O'DONNEL, K., RAO, L-X., LAIRD, G., COEY, J. M. D. Metastable iron nitrides by mechanical alloying. Physica status solidi (a). 1996, vol. 153, pp. 223-231.

[10] BOKHONOV, B., KORCHAGIN, M., BORISOVA, Yu. Formation of nanosized particles encapsulated in boron nitride during low-temperature annealing of mechanochemically treated Fe-BN mixtures. Journal of Alloys and Compounds. 2004, vol. 372, pp. 141-147.

[11] JIANG YANFENG, LIU JINMING, SURI PRANAV K., KENNEDY GREG, THADHANI NARESH N. FLANNIGAN DAVID J., WANG JIAN PING. Preparation of an $\alpha$ "- $-\mathrm{Fe}_{16} \mathrm{~N}_{2}$ magnet via a ball milling and shock compaction approach. Advanced Engineering Materials. 2016, vol. 18, no. 6, pp. 1009-1016. 
[12] MENUSHENKOV, V.P., MINKOVA, I.O., SAVCHENKO, A.G. Magnetic Properties and Structure of Materials Obtained from Solid-State Reaction Process between Iron and Boron Nitride Induced by Mechanical Milling. Physics of Metals and Metallography. 2019, Vol. 120, No. 13, pp. 1337-1340.

[13] MENUSHENKOV, V.P., MINKOVA, I.O., DOROFIEVICH, I.V., SHCHETININ, I.V., ZHUKOV, D.G., PARHOMENKO, Yu.N., SKRYLEVA, E.A., SAVCHENKO, A.G. Effect of high-energy ball milling on the structural phase state and magnetic properties of boron nitride and iron powder mixtures. Bulletin of the Russian Academy of Sciences: Physics. 2020, vol. 84, no. 7, pp. 871-878.

[14] YAMASHITA, S., MASUBUCHI, Y., NAKAZAWA, Y., OKAYAMA, T., TSUCHIYA, M., KIKKAWA, S. Crystal structure and magnetic properties of $\alpha "-\mathrm{Fe}_{16} \mathrm{~N}_{2}$ containing residual $\alpha$-Fe prepared by low-temperature ammonia nitridation. Journal of Solid State Chemistry. 2012, vol. 194, pp. 76-79.

[15] DIRBA, I., SCHWOBEL, C.A., DIOP, L.V.P., DUERRSCHNABEL, M. Synthesis, morphology, thermal stability and magnetic properties of $\alpha "-\mathrm{Fe}_{16} \mathrm{~N}_{2}$ nanoparticles obtained by hydrogen reduction of $\mathrm{y}-\mathrm{Fe}_{2} \mathrm{O}_{3}$ and subsequent nitrogenation. Acta Materialia. 2017, vol. 123, pp. 214-222.

[16] JIANG, Y., DABADE, V., F. ALLARD, L.F., LARA-CURZIO, E. Synthesis of $\alpha$ "- $F e_{16} \mathrm{~N}_{2}$ compound anisotropic magnet by the strained-wire method. Physical Review Applied. 2016, vol. 6, no. 2, pp. 1-10.

[17] JIANG, Y., MEHEDI, M.A., FU, E., WANG, Y. Synthesis of $\alpha$ "- $F e_{16} \mathrm{~N}_{2}$ compound free-standing foils with 20 MGOe magnetic energy product by nitrogen ion-implantation. Scientific Reports. 2016, vol. 6, 25436.

[18] SHELEKHOV, E.V., SVIRIDOVA, T.A. Programs for x-ray analysis of polycrystals. Metal Science and Heat Treatment. 2000, vol. 42, no. 7, pp. 309-313.

[19] TANIGUCHI, T., KIMOTO, K., TANSHO, M. et al. Phase transformation of amorphous boron nitride under high pressure. Journal of Non-Crystalline Solids. 2000, vol. 277, pp. 91-97.

[20] GROSVENOR, P., KOBE, B.A., BIESINGER, M.C., MCINTYRE, N.S. Investigation of multiplet splitting of Fe $2 p$ XPS spectra and bonding in iron compounds. Surface and Interface Analysis. 2004, vol. 36, pp. 1564-1574. 